\title{
Evaluation of groundwater potentials of Orogun, South-South part of Nigeria using electrical resistivity method
}

\author{
Sixtus Nwachukwu' ${ }^{1}$ Rasaq Bello ${ }^{2} \cdot$. Ayomide O. Balogun ${ }^{1}$
}

Received: 27 September 2018 / Accepted: 10 October 2019 / Published online: 16 October 2019

(c) The Author(s) 2019

\begin{abstract}
An investigation has been made of the groundwater potentials of Orogun Town, Ughelli North Local Government Area of Delta State, Nigeria, using electrical resistivity survey. This study motivated to determine electrical resistivity parameters of the area. The aim of this work is to use electrical resistivity method to explore the groundwater potentials of Orogun Town with the determination of its Dar Zarrouk parameters. A total of eight vertical electrical sounding (VES) were conducted with maximum electrode spacing of $150 \mathrm{~m}$. The data were acquired using ABEM SAS 4000 Terrameter and processed using IPI2win and Interpex softwares. The groundwater potentials of the area are evaluated based on the longitudinal conductance $(S)$, transverse resistance $(T)$, coefficient of electrical anisotropy $(\lambda)$, resistivity for the formation $\left(\rho_{\mathrm{m}}\right)$, reflection coefficient $\left(R_{\mathrm{C}}\right)$ and resistivity contrast $\left(F_{\mathrm{C}}\right)$. The results reveal four subsurface geoelectric layers in seven of the eight VES while one VES revealed three subsurface geoelectric layers. Resistivity values for all the layers in the study area are very high, higher than what is expected in a sedimentary basin as we have in the study area. The resistivity values range from $8470 \Omega \mathrm{m}$ (layer 1 , VES 7) to $118,030,000 \Omega \mathrm{m}$ (layer 3, VES 8). Depth to aquifer in the study area ranged from $1.61 \mathrm{~m}$ (VES 2) to $12.41 \mathrm{~m}$ (VES 1), while resistivity values of the aquifer ranged from 64,182 $\Omega \mathrm{m}$ (VES 3) to 118,030,000 $\Omega \mathrm{m}$ (VES 8). The results from the formation parameters evaluated showed that the area has good groundwater potential but might have been highly contaminated, especially from hydrocarbon sources and other man-made pollutants. The suggested contamination of the aquifer is as a result of the high values of resistivity of the aquifer layers.
\end{abstract}

Keywords Aquifer $\cdot$ Formation parameters $\cdot$ Geoelectric layers $\cdot$ Groundwater $\cdot$ Resistivity

\section{Introduction}

Electrical resistivity survey, a geophysical survey technique, has proved to be an effective and a reliable tool in locating viable aquifers for continuous and regular water supply (Adeniji et al. 2013). This method has the advantage of nondestructive effect on the environment, cost-effective, rapid and quick survey time and less ambiguity interpretations of the results when compared to other geophysical survey methods. The most popular configuration in vertical electrical sounding (VES) is the conventional Schlumberger array, which has a symmetrical layout with electrodes spread on

Rasaq Bello

bellomo68@yahoo.com

1 Department of Physics, University of Port Harcourt, Port Harcourt, Nigeria

2 Department of Physics, Federal University of Kashere, Gombe, Gombe State, Nigeria either sides of the array spread (Oladunjoye and Jekayinfa 2015; Olorunfemi et al. 2005).

Geophysical resistivity methods are based on the effective response of the earth to the flow of subsurface electrical current. The method involves passing electrical current into the ground by means of two current electrodes $\mathrm{AB}$ and two potential electrodes $\mathrm{MN}$ used to record the resultant potential difference between them, thereby resulting in the measurement of electrical impedance (Egbai 2013).

Electrical resistivity is widely used for hydrogeological studies, because the acquired data are mainly controlled by lithological conditions of the aquifer. The method is also useful in the correlation of lithological facies between wells (Obianwu et al. 2015). VESs, when combined with other geophysical methods, geologic mapping and available well data can greatly assist in the location and completion of water wells in bedrock areas of complex hydrogeology. The VES method is usually considered more suitable for the subsurface investigation of geologic environments consisting 
of horizontal or nearly horizontal layers, such as occur in unconsolidated sedimentary sequences (Ojekunle et al. 2015; Badmus and Olatinsu 2012; Alile et al. 2008).

According to the work of Laouini et al. (2017) on the delineation of aquifers using Dar Zarrouk parameters in parts of Akwa Ibom, Niger Delta Nigeria, the results showed that the area is vulnerable to contamination due to high permeability in the aquiferous layer. The study also indicated the area to be of high yield for groundwater. The work of Aweto and Akpoborie (2015) on estimating aquifer parameters using geoelectric sounding carried out at Orerokpe, Western Niger Delta, to determine the transmissivity and hydraulic conductivity of the study area revealed that the area has high groundwater potentials.

In their work on lithology identification and underground water conditions in Jeddo using geophysical and geochemical methods, Iserhien-Emekeme et al. (2017) showed that from the water quality index of the study area, the groundwater is of poor quality and requires some remediation before it can be used for domestic and industrial purposes. In his work on aquifer assessment in part of Niger Delta, Warmate (2016) extracted Dar Zarrouk parameters from geoelectric data and converted them to hygrological properties. The study area revealed high prolific aquiferous zones with resistivity $>1000 \Omega \mathrm{m}$. The work showed that the area would be vulnerable to contamination with high groundwater potentials.

The aim of this work is to carry out geoelectric investigation (VESs) in Orogun, Ughelli North Local Government Area of Delta State, to study the electrical resistivity parameters of the area for groundwater exploration.

The objectives of the study are to determine the lithology of the study area, aquifer protective capacity of the study area, and determine the Dar Zarrouk parameters of the subsurface rocks in the area in order to delineate the subsurface layers for groundwater potential zones in the study area.

\section{Materials and methods}

\section{Study area}

Orogun is one of the major towns in Ughelli North Local Government Area of Delta State. The town lies between latitude $5^{\circ} 30^{\prime} \mathrm{N}$ and $5^{\circ} 40^{\prime} \mathrm{N}$ and longitude $5^{\circ} 56^{\prime} \mathrm{E}$ and $6^{\circ} 11^{\prime} \mathrm{E}$. The town is bounded in the north by Ogunu Abraka, east by Emonu Orogun and west by Amai.

Orogun is a typical rainforest with about 7 months of rainfall in a year while the total precipitation in the area is put at $2950 \mathrm{~mm}$ of rainfall per annum. The study area is swampy due to the abundant rainfall, its closeness to the delta region and sea. These factors have serious impact on the subsurface water resulting in high pollution and corrosiveness of water in the area. Oil exploration and production activities have also contributed to water pollution in the area.

Orogun is a low-lying region of $0-100 \mathrm{~m}$ above sea level with average elevation of $10 \mathrm{~m}$. The study area falls within the Niger Delta region which is characterized by nearly flat tomography sloping very seaward (Akpokodje and Etu-Efeotor 1987). This area lies in the sedimentary basin and is devoid of any outcrop. The study area is shown in Fig. 1.

The electrical resistivity method was used for this study with the use of Schlumberger array of VES. Eight (8) sounding points were selected in the study area. VES measures vertical variation in ground resistivity with depth in respect to a fixed station. This is carried out by gradually increasing the inter-electrodes spacing at about a fixed center of array (Akanmu and Adewumi 2016; Telford et al. 1990). Conventional Schlumberger array utilizes four-electrode system which are arranged linearly with different inter-electrode spacing, the potential electrode remains partially fixed at the center of the spread, and the current electrode is expanded symmetrically about the center of the spread (Fig. 2) as described by Telford et al. (1978) and Parasnis (1986). The geometric factor is

$K=\pi\left[\frac{\left(\frac{A B}{2}\right)^{2}-\left(\frac{M N}{2}\right)^{2}}{M N}\right]$

The observed field data were converted to apparent resistivity $\left(\rho_{\mathrm{a}}\right)$ values using Eq. 2:

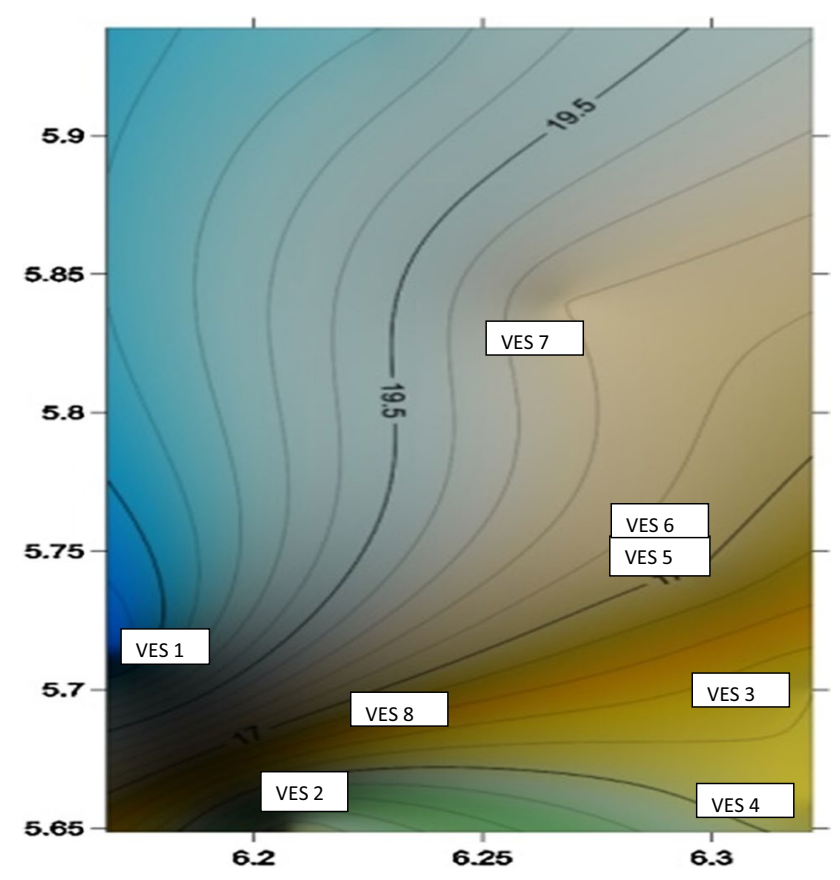

Fig. 1 Location map with VES points on the map 


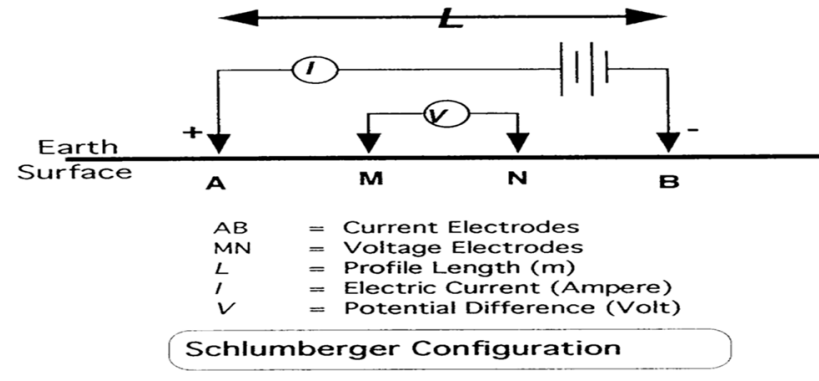

Fig. 2 Schlumberger array of vertical electrical sounding

$\rho_{\mathrm{a}}=R K$

$\rho_{\mathrm{a}}=\pi\left[\frac{\left(\frac{A B}{2}\right)^{2}-\left(\frac{M N}{2}\right)^{2}}{M N}\right] R$

In this array, the measuring electrodes are placed closely together such that the ratio of the measured voltage to the separation is approximately equal to the voltage gradient at the midpoint of the current spread.

The apparent resistivity values obtained from Eq. (2) were plotted using IPI2win software against the half current electrode separation spacing. From these plots, qualitative deductions such as the resistivity of the first or top layer, the depth of each layer and the curve signatures or types were made. The resistivities and thicknesses of various layers were improved upon by employing an automatic iterative computer program. Interpex computer software was employed for carrying out the iteration and inversion processes. Each iteration process was conducted for each sounding station until the root mean square (RMS) error of lower than $5 \%$ was obtained (Adeniji et al. 2013).

The electrical resistivity parameters of longitudinal conductance $(S)$, transverse resistance $(T)$, coefficient of electrical anisotropy $(\lambda)$, resistivity for the formation $\left(\rho_{\mathrm{m}}\right)$, reflection coefficient $\left(R_{\mathrm{C}}\right)$ and resistivity contrast $\left(F_{\mathrm{C}}\right)$ reflecting the characteristics of layered earth were determined in this work in addition to determination of longitudinal resistivity and transverse resistivity of the study area.

When the current flows parallel to the geoelectric boundaries, the parameter that influences current flow is the longitudinal conductance $(S)$ and when the current flows normal to the bed boundaries, the transverse resistance $(T)$ is significant (Telford et al. 1978). The ' $S$ ' and ' $T$ ' values are also known as Dar Zarrouk parameters and, for a layer of thickness ' $h$ ' and resistivity ' $\rho$ ', are defined as:

$S=\sum_{i=1} \frac{h_{i}}{\rho_{i}}$ and

$T=\sum_{i=1} h_{i} \rho_{i}$

When a number of layers with thicknesses of $h_{1}, h_{2}, h_{3}, \ldots$ transverse resistances of $T_{1}, T_{2}, T_{3}, \ldots$ and conductance of $S_{1}, S_{2}, S_{3}, \ldots$, respectively, are involved in a geoelectric section, their total longitudinal conductance $(S)$ or total transverse resistance $(T)$ may have to be considered and is given by:

$S=S_{1}+S_{2}+S_{3}+\cdots \quad$ where $S_{1}=\frac{h_{1}}{\rho_{1}}$

and

$T=T_{1}+T_{2}+T_{3}+\cdots \quad$ where $T_{1}=h_{1} \rho_{1}$

Increases in the value of ' $S$ ' from one sounding station to the next indicate an increase in the total thickness of the sedimentary section, a decrease in average longitudinal resistivity $\left(\rho_{\mathrm{L}}\right)$ or both.

When the value of ' $T$ ' increases from one sounding station to the next, this generally means that the thickness of the resistive layer in the section also increases. The increase in ' $T$ ' might be caused also by an increase in the resistivity values.

If the total thickness of the layers in the geoelectric section considered is $H$, then the average longitudinal resistivity $\rho_{\mathrm{L}}$ is given by

$\rho_{\mathrm{L}}=\sum_{i=1} \frac{h_{i}}{s_{i}}$

And the average transverse resistance $\rho_{1}$ is given by

$\rho_{1}=\sum T_{i} / h_{i}$

$\rho_{1}$ is always greater than $\rho_{\mathrm{L}}$. Therefore, the entire section will thus be anisotropic with regard to electrical resistivity. The coefficient of electrical anisotropy is defined as

$\lambda=\sqrt{\frac{\rho_{1}}{\rho_{\mathrm{L}}}}$

where $\lambda$ is real and greater than 1 .

A mean value of resistivity for the formation $\left(\rho_{\mathrm{m}}\right)$ can be defined as

$\rho_{\mathrm{m}}=\sqrt{\rho_{\mathrm{L}} \rho_{1}}$

The reflection coefficient $\left(R_{\mathrm{C}}\right)$ and resistivity contrast $\left(F_{\mathrm{C}}\right)$ of the fresh basement rock of the study area were calculated using the method of (Oladunjoye and Jekayinfa 2015).

$R_{\mathrm{C}}=\frac{\rho_{n}-\rho_{n-1}}{\rho_{n}+\rho_{n-1}}$ 
and

$F_{\mathrm{C}}=\frac{\rho_{n}}{\rho_{n-1}}$

where $\rho_{n}$ is the layer resistivity of the $n$th layer and $\rho_{n-1}$ is the layer resistivity overlying the nth layer.

\section{Results and discussion}

\section{VES results}

The summary of the interpreted electrical resistivity survey is presented in Table 1. Eight VESs were covered in this work. The geoelectric sections (Fig. 3a-h) revealed that the area is characterized by mainly four geoelectric subsurface layers with the exception of VES location 2 which shows a three-layer earth. VES locations 1,3 and 6 are characterized by HA curve types representing the presence of four geologic layers. The ascending right branch usually corresponds to the aquifer. VES location 2 which is the only VES characterized by three-layer earth reveals A-type curve, an ascending curve type. VES locations 4 and 7 are characterized by AA curve types representing the presence of four geologic layers. VES locations 5 and 8 which are characterized by four-layer earth exhibit $\mathrm{QH}$ and $\mathrm{AK}$ curve types, respectively.

\section{Discussion}

VES location 1, shown in Fig. 3a and Table 1, revealed a topsoil layer which is made up of loose unconsolidated sandy soil with thickness and resistivity values of $0.55 \mathrm{~m}$ and $188,340 \Omega \mathrm{m}$, respectively. The topsoil is followed by weathered layer with thickness and resistivity values of $0.87 \mathrm{~m}$ and $33,677 \Omega \mathrm{m}$, respectively, and is interpreted to be sandy-clayed soil. The weathered layer is followed by the aquifer layer with thickness and resistivity values of $10.99 \mathrm{~m}$ and 1,091,300 $\Omega \mathrm{m}$, respectively. This layer is interpreted to be coarse sandy and contained the aquifer. This aquifer layer is followed by a layer of fine-medium sand with resistivity value of 7,919,000 $\Omega \mathrm{m}$ and an undefined thickness.

VES location 2, shown in Fig. $3 \mathrm{~b}$ and Table 1, revealed a three-layer earth with resistivity values ranging from 12,321 to $6,815,100 \Omega \mathrm{m}$. The first layer is the topsoil and interpreted to be loose unconsolidated sandy soil with thickness and resistivity values of $0.53 \mathrm{~m}$ and $12,321 \Omega \mathrm{m}$, respectively. The topsoil is followed by the aquifer layer with thickness and resistivity values of $1.08 \mathrm{~m}$ and $267,960 \Omega \mathrm{m}$, respectively, and is interpreted to be coarse sandy and contained the aquifer. The aquifer layer in this location is of small thickness and shallow considering the fact that it is also located at just $0.53 \mathrm{~m}$ from the surface. This will make the water to be highly prone to contamination. The third and last layer in this location contains fine-medium sand with resistivity value of $6,815,100 \Omega \mathrm{m}$ with an undefined thickness.

Table 1 Summary table for the vertical electrical sounding interpretation

\begin{tabular}{|c|c|c|c|c|c|c|c|c|}
\hline & $\rho_{\mathrm{a}}(\Omega \mathrm{m})$ & $h(\mathrm{~m})$ & Depth (m) & Lithology & $\rho_{\mathrm{a}}(\Omega \mathrm{m})$ & $h(\mathrm{~m})$ & Depth (m) & Lithology \\
\hline VES 1 & & & & Fitting error: 2.25 & VES 2 & & & Fitting error: 2.50 \\
\hline Layer 1 & 188,340 & 0.55 & 0.55 & Topsoil & 12,321 & 0.53 & 0.53 & Topsoil \\
\hline Layer 2 & 33,677 & 0.87 & 1.42 & Weathered layer & 267,960 & 1.08 & 1.61 & Aquifer layer \\
\hline Layer 3 & $1,091,300$ & 10.99 & 12.41 & Aquifer layer & $6,815,100$ & - & - & Fine-medium sand \\
\hline Layer 4 & $7,919,000$ & - & - & Fine-medium sand & - & - & - & \\
\hline VES 3 & & & & Fitting error: 1.41 & VES 4 & & & Fitting error: 3.05 \\
\hline Layer 1 & 28,703 & 0.63 & 0.63 & Topsoil & 8954 & 0.91 & 0.91 & Topsoil \\
\hline Layer 2 & 9020 & 4.96 & 5.59 & Weathered layer & 13,008 & 2.26 & 3.17 & Weathered layer \\
\hline Layer 3 & 64,182 & 5.73 & 11.32 & Aquifer layer & 157,390 & 5.63 & 8.80 & Aquifer layer \\
\hline Layer 4 & $80,775,000$ & - & - & Fine-medium sand & $26,325,000$ & - & - & Fine-medium sand \\
\hline VES 5 & & & & Fitting error: 3.14 & VES 6 & & & Fitting error: 2.18 \\
\hline Layer 1 & 571,040 & 1.01 & 1.01 & Topsoil & 48,519 & 0.47 & 0.47 & Topsoil \\
\hline Layer 2 & 44,431 & 2.36 & 3.37 & Weathered layer & 9649 & 1.01 & 1.48 & Weathered Layer \\
\hline Layer 3 & 38,248 & 4.50 & 7.87 & Aquifer layer & 170,450 & 1.11 & 2.59 & Aquifer Layer \\
\hline Layer 4 & $70,329,000$ & - & - & Fine-medium sand & $86,416,000$ & - & - & Fine-medium sand \\
\hline VES 7 & & & & Fitting error: 1.10 & VES 8 & & & Fitting error: 2.50 \\
\hline Layer 1 & 8470 & 0.35 & 0.35 & Topsoil & 16,040 & 0.08 & 0.08 & Topsoil \\
\hline Layer 2 & 100,680 & 0.58 & 0.93 & Weathered layer & $1,052,100$ & 0.31 & 0.39 & Weathered layer \\
\hline Layer 3 & 114,270 & 4.54 & 5.47 & Aquifer layer & $118,030,000$ & 5.44 & 5.83 & Aquifer layer \\
\hline Layer 4 & $82,347,000$ & - & - & Fine-medium sand & $4,664,500$ & - & - & Fine-medium sand \\
\hline
\end{tabular}



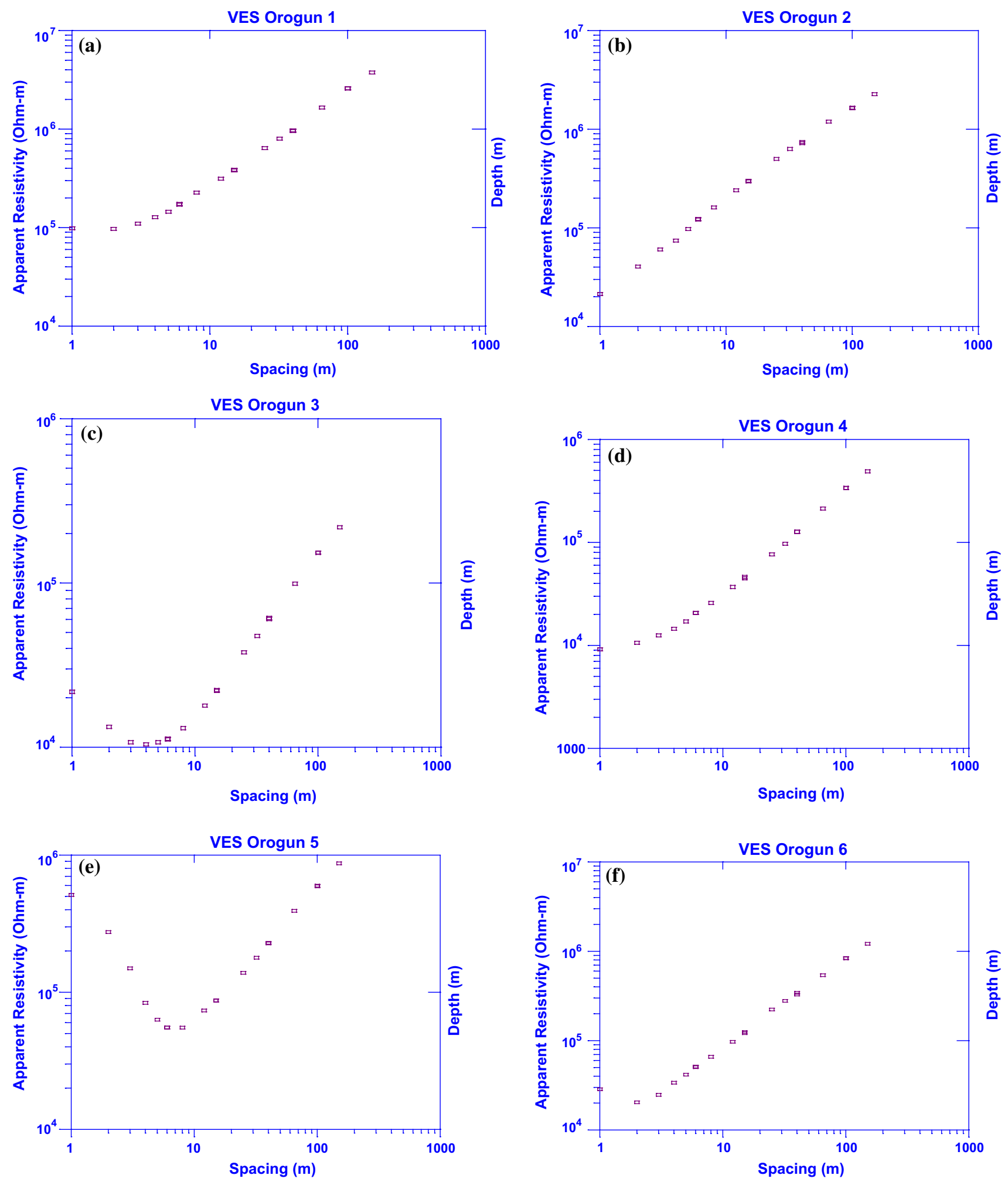

Fig. 3 VES curves for locations 1-8

VES location 3, shown in Fig. 3c and Table 1, revealed a four-layer earth. The first layer is the topsoil with thickness and resistivity values of $0.63 \mathrm{~m}$ and $28,703 \Omega \mathrm{m}$, respectively.
The topsoil is made up of loose unconsolidated sandy soil. The topsoil is followed by a weathered layer with thickness and resistivity values of $4.96 \mathrm{~m}$ and $9020 \Omega \mathrm{m}$, respectively, 

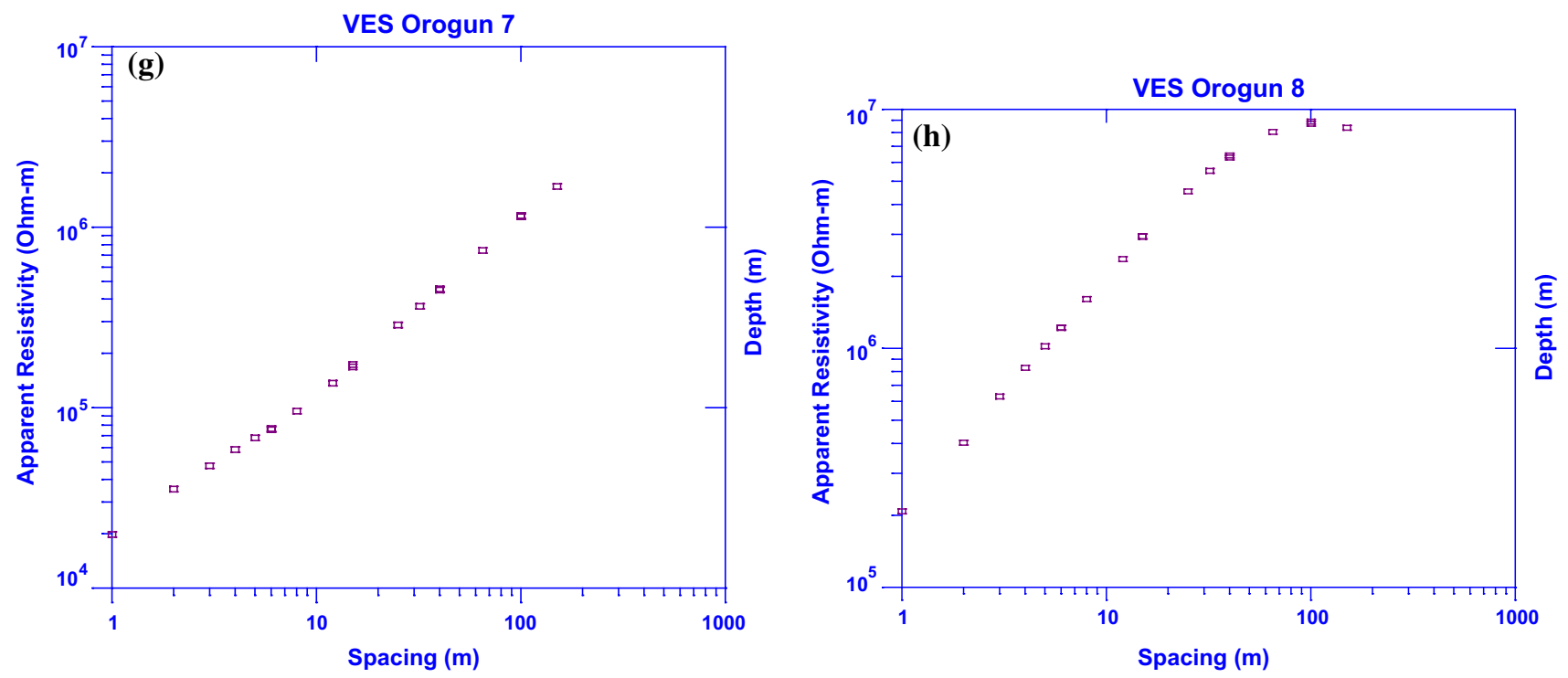

Fig. 3 (continued)

and is made up of sandy soil. The third layer which is the aquifer layer is made up of coarse sand and has a thickness of $5.73 \mathrm{~m}$ and resistivity value of $64,182 \Omega \mathrm{m}$. The fourth layer which contains fine-medium sand has a resistivity value of $80,775,000 \Omega \mathrm{m}$ with an undefined thickness.

VES location 4, shown in Fig. 3d and Table 1, revealed a four-layer earth. The first layer is the topsoil with thickness of $0.91 \mathrm{~m}$ and resistivity value of $8945 \Omega \mathrm{m}$. The topsoil is made up of loose unconsolidated sandy soil. The topsoil is followed by the weathered layer with thickness of $2.26 \mathrm{~m}$ and resistivity value of $13,008 \Omega \mathrm{m}$ and consists of sandy soil. The third layer which is the aquifer layer has a thickness of $5.63 \mathrm{~m}$ and resistivity value of $157,390 \Omega \mathrm{m}$. This layer is made up of coarse sandy soil. The fourth and last layer which contains fine-medium sand has a resistivity value of 2,635,000 $\Omega \mathrm{m}$ with an undefined thickness.

VES location 5, shown in Fig. 3e and Table 1, revealed a four-layer earth. The first layer is the topsoil with thickness of $1.01 \mathrm{~m}$ and resistivity value of $571,040 \Omega \mathrm{m}$. The topsoil is made up of loose unconsolidated soil. The topsoil is followed by a weathered layer with thickness of $2.36 \mathrm{~m}$ and resistivity value of $44,431 \Omega \mathrm{m}$ and is made up of sandy soil. This is followed by the third layer which is the aquifer layer with thickness of $4.50 \mathrm{~m}$ and resistivity value of $38,248 \Omega \mathrm{m}$. This layer consists of coarse sandy soil and contains the aquifer. The fourth layer which contains fine-medium sand has a resistivity value of 70,329,000 $\Omega \mathrm{m}$ with an undefined thickness.

VES location 6, shown in Fig. 3f and Table 1, is made up of four-layer earth. The VES data at the location showed that the topsoil is made up of loose unconsolidated sandy soil. The topsoil has a thickness of $0.47 \mathrm{~m}$ with resistivity value of $48,519 \Omega \mathrm{m}$. The topsoil is followed by a weathered layer with a thickness of $1.01 \mathrm{~m}$ and resistivity value of $9649 \Omega \mathrm{m}$. The weathered layer is made up of sandy soil. The third layer which is the aquifer layer is made up of coarse sandy soil with a thickness of $111 \mathrm{~m}$ and resistivity value of $170,450 \Omega \mathrm{m}$. The fourth and last layer which contains fine-medium sand has resistivity value of $86,416,000 \Omega \mathrm{m}$ with an undefined thickness.

VES location 7, shown in Fig. 3g and Table 1, is made up of four-layer earth. The VES data at the location showed that the first layer which is the topsoil is made up of loose unconsolidated sandy soil. The topsoil has a thickness of $0.35 \mathrm{~m}$ and resistivity value of $8470 \Omega \mathrm{m}$. The topsoil is followed by a weathered layer with a thickness of $0.58 \mathrm{~m}$ and resistivity value of 100,680 $\Omega \mathrm{m}$. The weathered layer is made up of sandy soil. The third layer which is the aquifer layer has a thickness of $4.54 \mathrm{~m}$ and a resistivity value of $114,270 \Omega \mathrm{m}$. This layer contains the aquifer in the location and is made up of coarse sandy soil. The fourth and last layer which contains fine-medium sand has a resistivity value of $82,347,000 \Omega \mathrm{m}$ with an undefined thickness.

VES location 8, shown in Fig. $3 \mathrm{~h}$ and Table 1, is made up of four-layer earth. The VES data at the location showed that the topsoil is made of loose unconsolidated sandy soil. The topsoil has a thickness of $0.08 \mathrm{~m}$ with resistivity value of $16,040 \Omega \mathrm{m}$. This is followed by a weathered layer with a thickness of $0.31 \mathrm{~m}$ and resistivity value of $1,052,100 \Omega \mathrm{m}$ and is made up of sandy soil. The weathered layer is followed by the third layer which is the aquifer layer with a thickness of $5.44 \mathrm{~m}$ and resistivity value of $118,030,000 \Omega \mathrm{m}$. This layer contains the aquifer in this location. The fourth layer which contains fine-medium sand has a resistivity value of 4,664,500 $\Omega \mathrm{m}$ with an undefined thickness. 
Table 2 Aquifer protective capacity parameters

\begin{tabular}{|c|c|c|c|c|}
\hline Apparent resistivity & Thickness & Depth & $\begin{array}{l}\text { Longitudinal conduct- } \\
\text { ance }(S)=(h / \rho)\end{array}$ & $\begin{array}{l}\text { Transverse } \\
\text { resistance } \\
(T)=(\rho * h)\end{array}$ \\
\hline \multicolumn{5}{|l|}{ VES 1} \\
\hline 188,340 & 0.55 & 0.55 & $2.92 \times 10^{-6}$ & $103,587.00$ \\
\hline 33,677 & 0.87 & 1.42 & $2.58 \times 10^{-5}$ & $29,298.99$ \\
\hline $1,091,300$ & 10.99 & 12.41 & $1.01 \times 10^{-5}$ & $11,993,387.00$ \\
\hline \multirow[t]{2}{*}{$7,919,000$} & - & - & & \\
\hline & & Total & $3.88 \times 10^{-5}$ & $12,126,273.00$ \\
\hline \multicolumn{5}{|l|}{ VES 2} \\
\hline 12,321 & 0.53 & 0.53 & $4.30 \times 10^{-5}$ & 6530.13 \\
\hline 267,960 & 1.08 & 1.61 & $4.03 \times 10^{-6}$ & $289,396.80$ \\
\hline \multirow[t]{2}{*}{$6,815,100$} & - & - & & \\
\hline & & & $4.71 \times 10^{-5}$ & $295,926.93$ \\
\hline \multicolumn{5}{|l|}{ VES 3} \\
\hline 28,703 & 0.63 & 0.63 & $2.20 \times 10^{-5}$ & $18,082.89$ \\
\hline 9020 & 4.96 & 5.59 & $5.50 \times 10^{-4}$ & $44,739.20$ \\
\hline 64,182 & 5.73 & 11.32 & $8.93 \times 10^{-5}$ & $367,762.86$ \\
\hline \multirow[t]{2}{*}{$80,775,000$} & - & - & & \\
\hline & & Total & $6.61 \times 10^{-4}$ & $430,584.95$ \\
\hline \multicolumn{5}{|l|}{ VES 4} \\
\hline 8954.5 & 0.91 & 0.91 & $1.02 \times 10^{-4}$ & 8148.60 \\
\hline 13,008 & 2.26 & 3.17 & $1.74 \times 10^{-4}$ & $29,398.08$ \\
\hline 157,390 & 5.63 & 8.8 & $3.58 \times 10^{-5}$ & $886,105.7$ \\
\hline \multirow[t]{2}{*}{$26,325,000$} & - & - & & \\
\hline & & Total & $3.11 \times 10^{-4}$ & $923,652.38$ \\
\hline \multicolumn{5}{|l|}{ VES 5} \\
\hline 571,040 & 1.01 & 1.01 & $1.77 \times 10^{-6}$ & $576,750.40$ \\
\hline 44,431 & 2.36 & 3.37 & $5.31 \times 10^{-5}$ & $104,857.16$ \\
\hline 38,248 & 4.5 & 7.87 & $1.18 \times 10^{-4}$ & $172,116.00$ \\
\hline \multirow[t]{2}{*}{$70,329,000$} & - & - & & \\
\hline & & Total & $1.73 \times 10^{-4}$ & $853,723.56$ \\
\hline \multicolumn{5}{|l|}{ VES 6} \\
\hline 48,519 & 0.47 & 0.47 & $9.69 \times 10^{-6}$ & $22,803.93$ \\
\hline 9649 & 1.01 & 1.48 & $1.05 \times 10^{-4}$ & 9745.49 \\
\hline 170,450 & 1.11 & 2.59 & $6.51 \times 10^{-6}$ & $189,199.50$ \\
\hline \multirow[t]{2}{*}{$86,416,000$} & - & - & & \\
\hline & & Total & $1.21 \times 10^{-4}$ & $221,748.92$ \\
\hline \multicolumn{5}{|l|}{ VES 7} \\
\hline 8470 & 0.35 & 0.35 & $4.13 \times 10^{-5}$ & 2964.50 \\
\hline 100,680 & 0.58 & 0.93 & $5.76 \times 10^{-6}$ & $58,394.40$ \\
\hline 114,270 & 4.54 & 5.47 & $3.97 \times 10^{-5}$ & $518,785.80$ \\
\hline \multirow[t]{2}{*}{$82,347,000$} & - & - & & \\
\hline & & Total & $8.68 \times 10^{-5}$ & $580,144.70$ \\
\hline \multicolumn{5}{|l|}{ VES 8} \\
\hline 16,040 & 0.08 & 0.08 & $4.99 \times 10^{-6}$ & 1283.20 \\
\hline $1,052,100$ & 0.31 & 0.39 & $2.95 \times 10^{-7}$ & $326,151.00$ \\
\hline $118,030,000$ & 5.44 & 5.83 & $4.61 \times 10^{-8}$ & $642,083,200.00$ \\
\hline \multirow[t]{2}{*}{$4,664,500$} & - & - & & \\
\hline & & Total & $5.33 \times 10^{-6}$ & $642,410,634.00$ \\
\hline
\end{tabular}



protective capacity rating (Olusegun et al. 2016)
Table 3 Table showing aquifer

\begin{tabular}{ll}
\hline Rating & Remarks \\
\hline Greater than 10 & Excellent \\
$5-10$ & Very good \\
$0.2-4.9$ & Moderate \\
$0.1-0.19$ & Weak \\
Less than 0.1 & Poor \\
\hline
\end{tabular}

All the VES locations surveyed in this work have highresistivity values compared to what should be expected in a sedimentary basin of Niger Delta. This could be due to a combination of many factors ranging from errors in the field during data acquisition to contamination of the environment either arising from oil exploration and production activities in the area or other natural/man-made pollutants. The aquifer level in the study area is shallow which is another indication that the area is prone to contamination.

\section{Aquifer protective capacity}

The aquifer protective capacity for the study area was determined using the parameters longitudinal conductance $(S)$ and transverse resistance $(T)$ as presented in Table 2 and the aquifer protective capacity rating as presented in Table 3.

Variation in longitudinal conductance from one VES point to the other VES points indicated changes in the total thickness of low-resistivity materials (Worthington 1977; Glain 1979). The total longitudinal conductance $(S)$ is one of the geoelectrical parameters used to determine target areas of groundwater potentials. While low $T$ values are associated with low-resistivity formation (such as clayed soil) and a relatively shallow basement large, higher $T$ values are characteristics of high-resistivity formations and relatively deeper occurrence of the basement. Very high transverse resistance values correspond to very highly resistive formations in the subsurface.
From transverse resistance values, it is also possible to determine the direction of flow of groundwater in the aquifer. The total transverse resistance $(T)$ is one of the geoelectric parameters used to define the largest area of groundwater potential. It has a direct relation with transmissivity, and the highest $T$ values reflect most likely the highest transmissivity values of the aquifers or aquifer zones and vice versa.

For the study area, the area is characterized by very low values of longitudinal conductance with values far less than 0.1 in all the areas surveyed (Table 2). This showed that the area surveyed has very poor aquifer protective capacity. The area also showed high values of transverse resistance which indicated high-resistivity formations in the study area.

The aquifer in the study area may be prone to contamination resulting from short residence time in the coarse sand layers. The thicknesses of the overlain layers for the aquifers are not enough to protect the aquifers from percolating fluids. Usually, groundwater is given protection by geological barriers/layers having sufficient thickness and also called protective layers and low hydraulic conductivity. Silts and clays are suitable protective layers and when they are found as thick layers above aquifer, they constitute a protective cover (Olusegun et al. 2016). These conditions are not the case for this study.

\section{Dar Zarrouk parameters}

The groundwater potentials of the area evaluated based on the following indices: weathered layer thickness, resistivity of overburden thickness, transverse resistance $(T)$, coefficient of electrical anisotropy $(\lambda)$, reflection coefficient $\left(R_{\mathrm{C}}\right)$, formation resistivity $\left(\rho_{\mathrm{m}}\right)$ and resistivity contrast $\left(F_{\mathrm{C}}\right)$. The weathered or fracture layer constitute the water saturation zone are aquifer units. Locations where weathered layer thickness $>25 \mathrm{~m}$ and of a low clay content are indicated by the resistivity range $(<60 \Omega \mathrm{m})$ value are categorized to be the area of high groundwater potentials (Kumar et al. 2001). Values of various formation parameters are presented in Table 4.

Table 4 Evaluation of Dar Zarrouk parameters

\begin{tabular}{lcccccc}
\hline VES & $\begin{array}{l}\text { Reflection coeffi- } \\
\text { cient }\left(R_{\mathrm{C}}\right)=\frac{\rho_{n}-\rho_{n-1}}{\rho_{n}+\rho_{n-1}}\end{array}$ & $\begin{array}{l}\text { Resistivity con- } \\
\text { trast }\left(F_{\mathrm{C}}\right)=\frac{\rho_{n}}{\rho_{n-1}}\end{array}$ & $\begin{array}{l}\text { Longitudinal resistiv- } \\
\text { ity }\left(\rho_{\mathrm{L}}\right)=\frac{h}{S}(\Omega \mathrm{m})\end{array}$ & $\begin{array}{l}\text { Transverse resistiv- } \\
\text { ity }\left(\rho_{\mathrm{l}}\right)=\frac{T}{h}(\Omega \mathrm{m})\end{array}$ & $\begin{array}{l}\text { Coefficient of anisot- } \\
\text { ropy }(\lambda)=\sqrt{\frac{\rho_{l}}{\rho_{L}}}\end{array}$ & $\begin{array}{l}\text { Resistivity of forma- } \\
\text { tion }\left(\rho_{\mathrm{m}}\right)=\sqrt{\rho_{\mathrm{l}} \rho_{\mathrm{L}}} \\
(\Omega \mathrm{m})\end{array}$ \\
\hline 1 & 0.76 & 7.26 & $319,644.0$ & $977,137.20$ & 1.75 & $558,870.0$ \\
2 & 0.92 & 25.43 & $34,221.5$ & $183,805.50$ & 2.32 & $79,310.2$ \\
3 & 1.00 & 1258.53 & $17,122.6$ & $38,037.54$ & 1.49 & $25,520.6$ \\
4 & 0.99 & 167.26 & $28,283.5$ & $104,960.50$ & 1.93 & $54,485.4$ \\
5 & 1.00 & 1838.76 & $45,613.1$ & $108,478.20$ & 1.54 & $70,342.3$ \\
6 & 1.00 & 506.99 & $21,427.4$ & $85,617.34$ & 2.00 & $42,831.7$ \\
7 & 1.00 & 720.63 & $63,008.6$ & $106,059.40$ & 1.30 & $81,747.5$ \\
8 & -0.92 & 0.04 & $1,094,164.0$ & $1.1 \times 10^{8}$ & 10.04 & $1.1 \times 10^{7}$ \\
\hline
\end{tabular}




\section{Reflection coefficient}

The reflection coefficient $\left(R_{\mathrm{C}}\right)$ values of the study area are presented in Table 4. Areas of low reflection coefficient value have high water potentials. It is a measure of the degree of fractures of an area.

The bedrock interface coefficient is an important parameter which shows that a bedrock fracture is filled with water. There must be a direct correlation with the anisotropy coefficient value for these parameters to be considered. The reflection coefficient values for this study range from 0.76 to 1.00 for all the VES locations except for VES location 8 which has value of -0.92 . For most of the locations studied in this work, the reflection and anisotropy coefficient values showed linear relationship. Thus, the parameter could be considered (together with other parameters) as being good factor for borehole development.

\section{Resistivity contrast}

Resistivity contrast values can provide an insight into groundwater potential of an area. In this study, the resistivity contrast values for VES 1-7 range from 7.26 to 1838.76 , while that of VES 8 was 0.04 . The study revealed that VES 1 and 8 has the highest potential for groundwater exploration.

\section{Coefficient of anisotropy}

Coefficient of anisotropy $(\lambda)$ can provide insight into the aquifer nature of the basement rock, and low $\lambda$ values may be indicating high-density water-filled fractures. The coefficient of anisotropy was determined for this work even though, the study area is not a basement complex, it was considered necessary to determine it to see if it can also provide an insight into groundwater potential in the study area. The coefficient of anisotropy values in the study area range from 1.30 to 2.32 for VES 1-7 and 10.04 for VES 8. These values are considered high $\lambda$ values.

Generally, the electrical anisotropy is 1 and does not exceed 2 in most of the geological conditions (Zohdy 1974; Anudu et al. 2011), and compact rock at shallow depth increases the electrical anisotropy. Hence, these areas can be associated with low porosity and permeability.

\section{Resistivity of formation}

The formation resistivity factor measures the influence of pore structure on the resistance of sample. When formation contains hydrocarbon, its resistivity will be very high (Okhue and Olorunfemi 1991). The resistivity of formation values in this study is very high which is an indication that the groundwater in the study area might have been contaminated with hydrocarbon.

\section{Conclusions}

In this work, the electrical resistivity sounding method using the Schlumberger array configuration was used to explore the study area. The work was carried out in Orogun Town, Ughelli North Local Government Area of Delta State, Nigeria, to evaluate the groundwater potentials of the area. The results provide data on the formation parameters. The investigation involved eight vertical electrical soundings covering parts of Orogun Town.

The results revealed four geoelectric layers in VES 1, 3-8, while VES 2 revealed three geoelectric layers. The study area revealed a shallow aquifer level with depth to aquifer less that $4 \mathrm{~m}$ in most of the study areas except in VES 3 which has depth to aquifer of $5.59 \mathrm{~m}$.

Resistivity values for all the layers in the study area are very high, higher than what is expected in a sedimentary basin as we have in the study area. The resistivity values range from $8470 \Omega \mathrm{m}$ (layer 1, VES 7) to $118,030,000 \Omega \mathrm{m}$ (layer 3, VES 8).

Formation parameters were also evaluated, and the parameters evaluated include: longitudinal conductance, transverse resistance, reflection coefficient, resistivity contrast, longitudinal resistivity, transverse resistivity, coefficient of anisotropy and resistivity of formation. The results from these evaluated parameters showed that the area has good groundwater potential but might have been highly polluted especially from hydrocarbon sources and other manmade pollutants.

Open Access This article is distributed under the terms of the Creative Commons Attribution 4.0 International License (http://creativeco mmons.org/licenses/by/4.0/), which permits unrestricted use, distribution, and reproduction in any medium, provided you give appropriate credit to the original author(s) and the source, provide a link to the Creative Commons license, and indicate if changes were made.

\section{References}

Adeniji AE, Obiora DN, Omonona OV, Ayuba R (2013) Geoelectrical evaluation of groundwater potentials of Bwari basement area, Central Nigeria. Int J Phys Sci 8(25):1350-1361. https://doi. org/10.5897/IJPS2013.3951

Akanmu TO, Adewumi AJ (2016) A multi-technique approach to aquifer characterization of basement complex Terrain: a case study of the polytechnic, Ibadan, Southwestern Nigeria. ARPN J Earth Sci 5(2), ISSN 2305-493X. www.arpnjournals.com

Akpokodje EG, Etu-Efeotor JO (1987) The occurrence and economic potential of clean sand deposits of the Niger Delta. J Afr Earth Sci 6(1):61-65 
Alile MO, Jegede SI, Ehigiator OM (2008) Underground water exploration using electrical method in Edo State, Nigeria. Asian J Sci $1(1): 38-42$

Anudu GK, Onuba LN, Ufondu LS (2011) Geoelectric sounding for groundwater exploration in the crystalline basement terrain around Onipe and adjoining areas, Southwestern Nigeria. J Appl Technol Environ Sanit 1(4):343-354

Aweto KE, Akpoborie IA (2015) Estimating aquifer parameters with geoelectric soundings: case study from the shallow Benin formation at Orerokpe, Western Niger Delta, Nigeria. Br J Appl Sci Technol 6(5):486-496

Badmus BS, Olatinsu OB (2012) Geophysical characterization of basement rocks and groundwater potentials using electrical sounding data from Odeda Quarry site, South Western, Nigeria. Asian J Earth Sci 5(3):79-87

Egbai JC (2013) Aquifer comparibility and formation strata in Orogun and Osubi (Ugolo) area of delta state using electrical resistivity method. Int J Res Rev Appl Sci 14(3):682-691

Glain DL (1979) Use of longitudinal conductance in vertical electrical soundings induced potential method for solving hydrogeolocial problems. Vestrik Mosk Univ Geol 34:74-100

Iserhien-Emekeme R, Merrious OO, Musa B, Ochuko A (2017) Lithological identification and underground water conditions in Jeddo using geophysical and geochemical methods. Hydrology 4(42):115. https://doi.org/10.3390/hydrology4030042

Kumar MS, Gnanasundar D, Elango L (2001) Geophysical studies to determine hydraulic characteristics of an alluvial aquifer. J Environ Hydrol 9(15):1-7

Laouini G, Sunday EE, Okechukwu EA (2017) Delineation of aquifers using Dar Zarrouk parameters in parts of Akwa Ibom, Niger Delta, Nigeria. J Hydrogeol Hydrol Eng 6(1):1-8. https://doi. org/10.4172/2325-9647.1000151

Obianwu VI, Atan OE, Okiwelu AA (2015) Determination of aquifer position using electric geophysical method. Appl Phys Res $7(2): 83-92$

Ojekunle VO, Shanxiong C, Ojekunle ZO, Oloruntola MO, Jian L (2015) Determination of ground water resources in Elekuro and
Environs, Abeokuta: using the geoelectric method (vertical electrical sounding). In: environmental sustainability in transportation infrastructure. ASCE conference proceedings, pp 1-24

Okhue ET, Olorunfemi MO (1991) Electrical resistivity investigation of a typical basement complex area-the Obafemi Awolowo University campus case study. J Min Geol 27(2):66-70

Oladunjoye M, Jekayinfa S (2015) Efficacy of hummel (modified Schlumberger) arrays of vertical electrical sounding in groundwater exploration: case study of parts of Ibadan Metropolis, Southwestern Nigeria. J Geophys. https://doi.org/10.1155/2015/612303

Olorunfemi MO, Ojo JS, Idornigie AI, Oyetoran WE (2005) Geophysical investigation of structural failure of a factory site in Asaba area, southern Nigeria. J Min Geol 41(1):111-121

Olusegun OA, Adeolu OO, Dolapo FA (2016) Geophysical investigation for groundwater potential and aquifer protective capacity around Osun State University (UNIOSUN) College of Health Sciences. Am J Water Resour 4(6):137-143. https://doi.org/10.12691 lajwr-4-6-3

Parasnis DS (1986) Principles of applied geophysics, 5th edn. Chapman and Hall, London

Telford WM, Geldart LP, Sheriff RE, Keys DA (1978) Applied geophysics. Cambridge University Press, New York

Telford WM, Geldart LP, Sheriff RE (1990) Applied geophysics, 2nd edn. Cambridge University Press, Cambridge

Warmate T (2016) Aquifer assessment in part of Niger Delta. J Multidiscip Eng Sci Stud 2(12):1220-1225

Worthington PF (1977) Influence of matrix conduction upon hydro geophysical relationships in arenaceous aquifers. Water Resour Res 13(1):87-92

Zohdy E (1974) Application of surface geophysicas to groundwater investigations: techniques of water resources investigations of the UD Geological survey Book, vol 2, pp 5-60

Publisher's Note Springer Nature remains neutral with regard to jurisdictional claims in published maps and institutional affiliations. 